\title{
WORD ASSOCIATION IN L1 AND L2
}

\section{An Exploratory Study of Response Types, Response Times, and Interlingual Mediation}

\author{
Tess Fitzpatrick and Cristina Izura \\ Swansea University
}

\begin{abstract}
Word association responses in first-language (L1) Spanish and secondlanguage (L2) English were investigated by means of response latencies and types of associative response produced. The primary aims were to establish whether (a) some response types are produced more often or faster than others, (b) participants' $L 2$ response time profiles mirror those of their $L 1$, and (c) participants' $L 2$ association responses are mediated by their $L 1$ and modulated by proficiency. Results indicate that responses are faster when a double association link is produced-that is, when the response is associated by form and meaning (postman $\rightarrow$ postbox) or meaning and collocation (spider $\rightarrow$ web). L2 response time profiles broadly mirror those of the $L 1$, although $L 2$ times are generally slower. A significant priming effect from $\mathrm{L} 1$ translation equivalents of cues used in the $\mathrm{L} 2$ association task was observed, suggesting $\mathrm{L} 1$ mediation in the production of $\mathrm{L} 2$ associative responses. Findings are discussed in light of the revised hierarchical model (Kroll \& Stewart, 1994). New approaches to modeling and understanding the bilingual lexicon are also suggested.
\end{abstract}

We would like to thank the editor and five anonymous SSLA reviewers for their very helpful comments on earlier drafts of this article. Thanks also go to Dr. Natividad HernándezMuñoz (University of Salamanca) for helping with the categorization of data and to participants for generously contributing their time to this project.

Address correspondence to: Tess Fitzpatrick, College of Arts and Humanities, Swansea University, Singleton Park, Swansea SA2 8PP, UK; e-mail: t.fitzpatrick@swansea.ac.uk. 
A number of important and influential studies in the 1960s and 1970s used word association behavior to draw inferences about the developmental organization of the first-language (L1) lexicon (e.g., Entwisle, 1966; Ervin, 1961; Lippman, 1971; McNeill, 1966; Nelson, 1977). A body of work subsequently emerged that used similar techniques in the exploration of the bilingual lexicon. Early studies of this kind examined the possibility of using responses from word association tasks as a measure of second-language (L2) proficiency, either by comparing L2 learners' responses with native-speaker norms (e.g., Kruse, Pankhurst, \& Sharwood Smith, 1987; Randall, 1980; Schmitt, 1998; Sökmen, 1993) or by comparing L1 and L2 vocabulary growth in terms of a shift in the type of associative response given (e.g., Politzer, 1978; Söderman, 1993). Research on L1 development had shown that around the age of 6 or 7, a shift from syntagmatic (e.g., right $\rightarrow$ foot) to paradigmatic (e.g., right $\rightarrow$ left) responses occurs (Entwisle, Forsyth, \& Muuss, 1964; Ervin). L2 researchers hypothesized that this shift must be a function of the restructuring of a growing lexicon and therefore must also occur in the developing L2.

However, the assumption that the processes of lexical acquisition, storage, and retrieval in a L2 will follow the same patterns, stages, and ultimate attainment as those in a L1 ignores three important facts. First, a high proportion of late bilingual speakers (subsequently referred to as bilinguals) have a well-formed L1 lexicon by the time they start learning a L2; therefore, changes in language behavior linked to intellectual development have already taken place for these L2 speakers. Second, the developing L2 lexicon makes considerable use of L1 lexical links and conceptual knowledge acquired during L1 learning (Koda, 1997; Kroll \& Tokowicz, 2005; Odlin, 1989). In consequence, L2 growth and changes might not be directly comparable to those changes taking place when the L1 was acquired in isolation. Meara $(1978,1983)$ and Laufer (1989), for example, have suggested that the organization of the L2 mental lexicon is heavily form-driven and more reliant on phonological information than is the L1 (see Singleton, 1999, for counterarguments and further discussion). Third, some important factors related to L2 learning, such as cultural differences and instruction method, have often been overlooked (see Kruse et al., 1987; Zareva, Schwanenflugel, \& Niklova, 2005, for further discussion). In sum, the underlying presupposition that the L2 of a bilingual speaker has to ultimately resemble the L1 of a monolingual counterpart has understandably resulted in inconclusive findings. As Grosjean (1989) stated, a bilingual speaker is not the equivalent of two monolingual speakers in one brain. Differences in intellectual and chronological age, culture, and language use, among other things, mean that the linguistic configuration of monolingual and bilingual speakers will differ, just as the linguistic configuration of the L1 will differ from that of any subsequently acquired language. 
It seems, then, that there is no easy parallel to be drawn between L1 and L2 word association behavior that can help with the measure of developing L2 proficiency. Recently, however, a number of studies have emerged that use L2 word association responses not as a potential measure of proficiency but as a tool to investigate and understand ways in which the bilingual lexicon is structured and accessed. The proficiency level of L2 speakers is certainly a relevant variable here, but these studies regard proficiency as an informing factor, rather than as a goal of measurement, which is a subtle but crucial difference (Grabois, 1999; Meara, 2007; Van Hell \& De Groot, 1998; Wilks, 2009; Wilks \& Meara, 2007; Wilks, Meara, \& Wolter, 2005; Wolter, 2002).

Following this line of research and in an attempt to further understanding of the way in which the lexicon of L2 learners is organized, Fitzpatrick (2006) used a novel categorization framework to compare the associative responses given by L1 and L2 users of English. She followed the well-practiced technique of grouping word association responses according to predetermined categories (Albrechtsen, Haastrup, \& Henriksen, 2008; Greidanus \& Nienhuis, 2001; Meara, 1983; Orita, 2002; Politzer, 1978; Singleton, 1999; Söderman, 1993). The new classification system comprised 4 main categories (meaning-based, form-based, position-based, and erratic associations) that were then divided into 17 subcategories, providing a more precise procedure for categorization. Fitzpatrick found not only clear group differences in the number of responses given in certain categories but also important individual variations in response profiles. In terms of group differences, L1 users produced significantly more responses in the categories meaning: defining synonym (e.g., sofa $\rightarrow$ couch) and position: collocation (e.g., black $\rightarrow$ coffee), whereas L2 users produced significantly more responses in the categories of meaning: context association (e.g., goals $\rightarrow$ football), meaning: conceptual association (e.g., immigration $\rightarrow$ politics), and form: similar in form only (e.g., soup $\rightarrow$ soap). The individual differences were further explored and results suggested that within individuals, response profiles are consistent across both the L1 and L2 (Fitzpatrick, 2007, 2009).

The assumption from these and similar studies (Albrechtsen et al., 2008; Riegel \& Zivian, 1972; Wolter, 2002) is that the number of responses made in a particular category can provide information about the organization, availability, and salient features of words and their concepts in the mental lexicon. This fits well with the widely accepted working metaphor of the lexicon as a network of word-nodes linking in particular ways with each other. In the present study, a similar categorization technique for word association responses in L1 and L2 will be used to investigate in which ways and under which conditions L1 and L2 responses differ, resemble each other, and interact. 


\section{WORD ASSOCIATIONS AND RESPONSE TIME DATA}

Until now, studies that use categorization frameworks to analyze word association data have used the number of responses given in certain categories as the dependent variable, and inferences and conclusions have been based on this measure. Fitzpatrick (2006) found that her native-speaker participants produced more responses in the defining synonym category than in any other category. Interpreting this finding, though, is not straightforward. To use the network metaphor, this finding might suggest that, for this group, synonymous links between items were the most useful, or perhaps the most accessible or salient or the most frequently encountered. In fact, it is difficult to be sure whether this result reveals something about the way in which items are accessed or about the way in which they are stored-although inevitably connected, these are not necessarily the same thing. It is likely that association responses reflect an interaction among the influence of a participant's group membership (child, adult, or L2 learner), their individual response tendency, features of the stimulus word itself (frequency, associative strength, syntactic class, etc.), and individuals' strategies for responding based on what they suspect the researcher is looking for (Altarriba, Bauer, \& Benvenuto, 1999; Brysbaert \& Ghyselinck, 2006; Fitzpatrick, 2007, 2009; RodriguezAranda \& Martinussen, 2006).

In an attempt to tease apart these variables, the present study instructed participants to produce associates as quickly as possible. As a result, two dependent variables were extracted for analysis: the number of responses given in each association category and the speed with which responses in each category are produced. Response time data have been used fairly widely in investigating the nature of the L1 and L2 mental lexicons (Besner, Smith, \& MacLeod, 1990; Chen \& Ng, 1989; Collins \& Quillian, 1969; Forster, 1992; Hermans, Bongaerts, De Bot, \& Schreuder, 1998; Kohnert, Bates, \& Hernandez, 1999; Schriefers, Meyer, \& Levelt, 1990). However, somehow they have rarely been applied to word association research. Speeding up responses and measuring the resulting reaction times offer the possibility of inferring properties of the lexicosemantic pathways that are less dependent on strategic processes (e.g., Costa \& Caramazza, 1999; De Groot, Borgwaldt, Bos, \& Van den Eijnden, 2002). Such inferences should be made with caution, however, because shorter reaction times might not always be an indication of the easiest or least complex response type (Wickelgren, 1977).

For example, when the fastest experimental performance also produces the highest error rates, there might be a combination of structural and functional characteristics influencing the data. However, it is very difficult to produce erroneous responses in word association tasks because almost 
any response is, in principle, valid. For this reason, in the present study it was considered appropriate to measure reaction time data from word association tasks in combination with the more traditional measure of number of associative responses per category. This approach makes it possible to reach more accurate conclusions regarding access, availability, and ease of responses. A second analysis made possible in the current study relates to L2 proficiency. Fitzpatrick (2009) reported that as proficiency increased, a learner's L2 association profile became more similar to their L1 profile in terms of the number of responses produced in each category. The use of reaction time data will allow for the investigation of whether, with increased proficiency, the L2 profile also becomes more similar to that of the L1 in terms of speed of responses.

\section{DUAL-LINK RESPONSE TYPES}

It is essential to note here that previous studies investigating word association responses through categorization techniques have only considered discrete categories, assuming that each response depends on only one kind of associative link. A response would therefore be classed as either syntagmatic (linked as a result of words co-occurring together in the language, as in chair $\rightarrow$ sit) or paradigmatic (linked as a result of belonging to the same grammatical class, such as chair $\rightarrow$ stool). The possibility that both types of association might play a role in activating one single response has never been accommodated in previous taxonomy systems, despite the fact that some common stimulus-response pairs match this interpretation well. For example, black frequently elicits the response white-an association that can be considered either syntagmatic (as in black and white film or as clear as black and white) or paradigmatic (black and white are both colors). The determination to classify responses into separate and discrete categories has led to frustrated attempts at categorization (e.g., Meara, 1983; Wolter, 2001), time-consuming methodological approaches (Fitzpatrick, 2006, conducted posttask interviews to determine which single category each response fit), and the use of catch-all categories (Maréchal, 1995, included a paradigmatic-syntagmatic category for such difficult cases). None of these studies accommodated the possibility that the cognitive processes underlying the production of a response could be influenced by more than one type of associative connection and therefore precluded recognition of the intricacies of the lexicosemantic system, which might be reflected in this type of associative response. The present study addresses this issue by extending Fitzpatrick's (2006) taxonomy and creating two additional categories for responses associated to the cue word by more than one link. These were form and meaning, such as pencil $\rightarrow$ pen, and meaning and collocation, such as pen $\rightarrow$ paper. 


\section{MEDIATION OF L2 RESPONSES THROUGH THE L1}

Word association data are considered by many researchers to provide a valuable insight into the mental lexicon because responses are assumed to be representative of lexicosemantic connections. According to lexical mediation models of L2 development such as the revised hierarchical model (Kroll \& Stewart, 1994), at the initial stages of learning, the forms of the newly learned words in the L2 access their meaning representations via their translation equivalents in the L1. This means that in a L2 word association task, an adult English native speaker starting to learn Portuguese will have to translate bolo "cake" into its L1 equivalent to access its meaning. The model claims that as the speaker gains proficiency in his or her L2, direct connections between L2 words and their meanings would be created and used. Therefore, it can be assumed that for a nonproficient bilingual to produce a L2 word association, the L2 cue word might be first translated into the L1 (e.g., bolo into cake). Then, an associated response, possibly in the L1, would be selected (e.g., birthday) and translated back to the L2 (e.g., aniversário) before the speaker produces it as the final response. Proficient bilinguals, however, would not need to go through the process of translating the cue word to the L1. Thus, according to the model, quantitative or qualitative differences might be found between nonproficient and proficient bilinguals.

The current study investigates the potential mediation of the L1 in L2 associative responses in Spanish-English bilinguals with different proficiency levels. Priming was the paradigm selected to assess this hypothesized L1 mediation. Priming occurs when the recognition or production of a target word is sped up by the preceding presentation of a related item, the so-called prime (e.g., a letter string, a word, or a picture). The assumption is that "activating the prime causes the target to be activated faster. Conversely, if a target word is activated faster (primed), you can be sure that the priming word must have been activated" (Altmann, 1997, pp. 71-72). A large number of studies with monolingual speakers (Bodner \& Masson, 2003; Grossi, 2006; Monsell, 1985) have reported short-term semantic priming effects (nurse priming doctor) with one or zero intervening items. This has been explained in terms of residual activation. Long-term semantic priming has also been reported (Becker, Moscovitch, Behrmann, \& Joordens, 1997; Joordens \& Becker, 1997; Tse \& Neely, 2007) and is accounted for in terms of incremental learning, whereby the connections involved in a particular processing pathway are strengthened by repeated activations: The higher the strength of these connections, the faster the subsequent processing. Incremental learning has been reported to be relatively insensitive to time (Damian \& Als, 2005). Long-lasting semantic priming across languages and across tasks has also been reported (La Heij, Hooglander, Kerling, \& Van der Velden, 1996; Sholl, Sankaranarayanan, \& Kroll, 
1995). For example, Sholl et al. asked 24 participants to complete a picture naming task followed by a translation task. They found that translation from the L1 to the L2 was facilitated for those words whose concepts had been activated in the previous task.

A similar rationale was applied to the present study. Immediately after participants completed the English (L2) word association task, they were presented with a word recognition task in their L1 (Spanish). Crucially, half of the words included in the recognition task were translation equivalents of some of the cue words that had appeared in the English association task. A facilitatory effect for these translated words was predicted if dominant bilinguals (particularly those with low proficiency in L2) associate words in the L2 by translating them first into their L1.

\section{SELECTION OF CUE WORDS}

A number of researchers (Fitzpatrick, 2006; Meara, 1983; Wolter, 2002) have expressed concern at the fact that word association stimuli are often not selected in a principled way. Indeed, word association studies have commonly disregarded the lexical and syntactic characteristics of the stimuli used as cue words and this might have introduced unwanted experimental influences, making the interpretation of their results difficult. A vast amount of data has shown that lexical and syntactic properties are important when individuals are processing words. For example, cognates, or words similar in meaning and form across languages, are processed more efficiently by bilingual speakers (Jared \& Kroll, 2001). Findings from a number of word association studies have indicated that word class can affect response behavior (e.g., Deese, 1962; Nissen \& Henriksen, 2006; Sökmen, 1993). Other factors that affect lexical processing include the frequency of the words, the age at which they are acquired, their degree of concreteness, their length, and their syntactic category (Morrison \& Ellis, 2000; Zevin \& Seidenberg, 2002, 2004). The study presented here addresses this methodological problem by using two sets of words (one in English and one in Spanish) derived from the same syntactic categories and matched in relevant lexical and semantic variables.

\section{THE STUDY}

\section{Research Questions}

The current study was guided by three research questions:

1. Are some response types more numerous or produced more quickly than others? This question will be addressed in both the L1 (Spanish) and the L2 (English). 
2. Do L2 response time profiles mirror those of the L1? Is this potential resemblance modulated by language proficiency? Differences between response time profiles in the L1 and L2 were predicted in accordance with the proposition that the linguistic configurations for the L1 and L2 are dynamic and different.

3. Are L2 word association responses mediated through the L1? Is this potential mediation dependent on language proficiency? According to the revised hierarchical model (Kroll \& Stewart, 1994), a stronger mediation of the L1 is predicted for low-proficiency bilinguals than for high-proficiency bilinguals.

In summary, the present study comprised an investigation of the type of word associations bilingual speakers elicit in their L1 and L2 and the speed at which these associations are produced. Additionally, the possibility that associations in the L2 were mediated by the L1 was explored. Two word association tasks and one lexical decision task were designed to address these issues.

\section{Method}

Two word association tasks were used: one in Spanish (the participants' L1) and one in English (the L2). These were discrete free word association tasks, in which individuals were asked to produce a single associate to each cue word. Participants also completed a lexical decision task to test the hypothesis that the L2 associations were mediated through the L1. If it was the case that in order to associate words in (L2) English, participants had to first translate the cue words into (L1) Spanish, those Spanish translations that had been already activated would be accessed more rapidly in a subsequent task than Spanish words not seen or accessed in any way during the word association testing session. In other words, a priming effect was predicted for those Spanish words whose translation equivalents had been previously seen as English cue words in the word association task.

\section{Participants}

Twenty-four native Spanish speakers (19 females and 5 males), who had started to learn English as a L2 at a mean age of 9 years old, took part in the study. Participants were an average of 26 years old (range: 20-49). All were studying or working in the United Kingdom. Their proficiency in English was measured at the end of the testing session (which comprised two word association tasks and one lexical decision task) 
using the Eurocentres Vocabulary Size Test (EVST; Meara \& Jones, 1990). The EVST is a receptive vocabulary size test that has shown high correlations with other measures of L2 proficiency (Meara, Lightbown, \& Halter, 1994). The test consists of a combination of real words (of different frequencies) and invented words. The individual has to indicate (by pressing a button) which words are familiar. The correct recognition of all the real words and rejection of all the invented words will lead to a ceiling score of 10,000 . As a group, participants had an upper intermediate proficiency level, with a mean score of 7,192 (range: $3,250-9,900)$. EVST scores are given in Table 1.

\section{Materials}

Word Association Tasks. Stimuli for the word association tasks consisted of 95 Spanish words (from Pérez \& Navalón, 2005) and 95 English words (from Bird, Franklin, \& Howard, 2001). The use of cognate words (similar in form and meaning across languages), interlingual homographs (similar in form across languages), and translation equivalents was avoided. The two word lists (in English and Spanish) were matched on number of letters, imageability (i.e., the degree to which a word can evoke a mental image), word frequency, syntactic class, and age of acquisition in English and Spanish as L1s. These lists are available upon request.

Lexical Decision Task. Seventy-two items were used as stimuli (36 real Spanish words and 36 invented words). Real words were divided into sets A and B (18 words in each set). Set A comprised the primed words. These were translation equivalents of 18 of the words used as cues in the English word association task. Set B consisted of the nonprimed words. These were 18 Spanish words that were not used as cues in the Spanish word association task and that were not translation equivalents of any items in the English word association task. As for the word association stimuli, none of the words selected was a cognate

Table 1. EVST scores

\begin{tabular}{lccc}
\hline Score & Low-proficiency group & High-proficiency group & All \\
\hline$M$ & 5,156 & 8,413 & 7,192 \\
$S D$ & 1,502 & 949 & 1,982 \\
Minimum & 3,250 & 7,550 & 3,250 \\
Maximum & 6,500 & 9,900 & 9,900 \\
\hline
\end{tabular}


or interlingual homograph (similar in form or meaning) in English and Spanish. The two sets of words were matched on word frequency, age of acquisition, imageability, and number of letters (based on data from Pérez \& Navalón, 2005). The invented words were created by changing one letter from real Spanish words in such way that the letter string remained orthographically and phonologically legal in the Spanish language. The two set lists of experimental words are available upon request.

\section{Procedure}

Participants first completed the two word association tasks: one in their L1 Spanish and one in their L2 English. They then completed the lexical decision task. All three tasks were presented to participants on a PC (Mertec, LG 52) using E-Prime software. Stimuli were shown in 18-point black Courier New font in the middle of a white screen background. Participants sat approximately $60 \mathrm{~cm}$ away from the computer screen. Each trial began with the presentation of a fixation cross in the middle of the screen for $1,000 \mathrm{~ms}$.

Word Association Tasks. Following the presentation of the fixation cross, the cue word appeared and remained on the screen until the participant made a response. Verbal responses triggered a voice key linked to a high-sensitivity microphone situated in front of the participant. The time between the appearance of the cue word and the onset of the oral response was measured. Immediately after the oral response was produced, the screen went blank for $500 \mathrm{~ms}$ and then a series of consecutive hyphens appeared in the middle of the screen indicating that the response should be typed. The time to input the transcribed response was not measured and participants could correct any mistakes. When they finished typing, they pressed the enter key, which triggered the beginning of the next trial. The experimenter noted any naming errors or computer failures.

Participants were told that words would be presented in the center of the screen and that their task was to say, as quickly as possible, the first word they thought of. They were informed that after that, a series of consecutive hyphens would be displayed on the screen for them to type the response they had just said. In this way, the specific responses and response times were recorded. Cue words were presented in a randomized order for each participant and all the participants completed the Spanish word association task first, followed by the English word association task. Participants were instructed to say paso "pass" if they did not know a stimulus word; paso was in fact only used in response to (L2) English stimuli. 
Lexical Decision Task. The lexical decision task was completed immediately after participants had finished the word association task in (L2) English. Following the 1,000 ms presentation of the fixation cross in the center of the screen, the real or invented word appeared and remained on the screen until a response was made. Participants pressed the P key on a standard qwerty keyboard if the item was a real word and the Q key if it was an invented word. The experiment began with 20 practice items (10 real words and 10 invented words). Real and invented words were randomized for each participant.

\section{RESULTS}

\section{Word Association Tasks}

Two word association datasets were produced for each participant: responses and response times for the 94 (L1) Spanish cue words and responses and response times for the 94 (L2) English cue words.

Preparing Data for Analysis. Although it is desirable to minimize data loss in any study, reaction time studies inevitably produce a certain amount of erroneous data due, for example, to mechanical malfunction or ambient noise. In this study, the problem is augmented by the stressful nature of the task (to give word associations as quickly as possible); occasionally, the pressure to respond quickly caused participants to produce fillers (e.g., er, $u m, o h)$ before the response word or to panic and say nothing. Eighteen of the 94 stimuli in the English (L2) word association task produced a response of paso "pass" in more than $50 \%$ of participants, indicating that the word was not known to them. These stimuli and all participants' responses to them were excluded from further analysis. Errors such as hesitations or computer failures, along with response times below $300 \mathrm{~ms}$ or above 7,000 ms were then excluded from the analyses. These represented $5.9 \%$ of response times for the (L1) Spanish word association task and 20\% for the (L2) English word association task. On the basis of the remaining observations, the overall mean and standard deviation of each participant's word association latencies were computed and any response times that were three standard deviations above or below each participant's mean were removed $(0.1 \%$ for the word association task in L1 Spanish and $16.3 \%$ for the word association task in L2 English). After these criteria were applied, data from six participants were removed from further analyses due to a high rate of invalid response times (more than $30 \%$ ).

Categorizing Data. Responses were then divided into six categories of association according to the lexicosemantic relationship between cue and response words: form and meaning, meaning and collocation, 
collocation, form, equivalent meaning, and nonequivalent meaning. Descriptions and examples for each category are given in Table 2. The data were categorized independently by two judges; in the very few cases in which categorizations differed, agreement was reached quickly when these cases were reviewed.

Comparing the L1 and L2: Number of Responses per Category. In general, participants gave fewer responses to the L2 stimuli than to the L1 stimuli. To compare response category behavior across the L1 and L2, therefore, the number of responses per participant in each category was converted to a percentage. Participants' percentages of responses per category and language are summarized in Figure 1.

The proportion of responses was submitted to a $2 \times 6$ ANOVA with category of response and language as within-subject factors. Results revealed a significant main effect of language, $F(1,17)=17.62, \mathrm{MSe}=$ $7.79, p<.05, \eta^{2}=.51$. The main effect of category of response was also

Table 2. Category names and descriptions

\begin{tabular}{|c|c|c|}
\hline Category name & Description & Examples \\
\hline $\begin{array}{l}\text { Form and } \\
\text { meaning }\end{array}$ & $\begin{array}{l}\text { Associative responses related to } \\
\text { the cue word in both their form } \\
\text { and general meaning }\end{array}$ & $\begin{array}{l}\text { newsagent } \rightarrow \text { newspaper } \\
\text { hairdresser } \rightarrow \text { hairdryer } \\
\text { milkman } \rightarrow \text { milk }\end{array}$ \\
\hline $\begin{array}{l}\text { Meaning and } \\
\text { collocation }\end{array}$ & $\begin{array}{l}\text { Associative responses related to } \\
\text { the cue word in both general } \\
\text { meaning and in their tendency } \\
\text { to co-occur in the language }\end{array}$ & $\begin{array}{l}\text { rubbish } \rightarrow \text { bin } \\
\text { peacock } \rightarrow \text { feather } \\
\text { pearl } \rightarrow \text { necklace } \\
\text { brother } \rightarrow \text { sister }\end{array}$ \\
\hline Collocation & $\begin{array}{l}\text { Associative responses whose only } \\
\text { relation to the cue word is their } \\
\text { tendency to co-occur in language }\end{array}$ & $\begin{array}{l}\text { captain } \rightarrow \text { Sparrow } \\
\quad(\text { film character }) \\
\text { bat } \rightarrow \text { man } \\
\text { goose } \rightarrow \text { bump }\end{array}$ \\
\hline Form & $\begin{array}{l}\text { Associative responses related to } \\
\text { the cue word only in their form }\end{array}$ & $\begin{array}{l}\text { mustard } \rightarrow \text { mustang } \\
\text { lark } \rightarrow \text { large }\end{array}$ \\
\hline $\begin{array}{l}\text { Equivalent } \\
\text { meaning }\end{array}$ & $\begin{array}{l}\text { Associative responses whose } \\
\text { meaning is equivalent to the } \\
\text { meaning of the cue word } \\
\text { (e.g., related by synonymy, } \\
\text { coordination, or superordination) }\end{array}$ & $\begin{array}{l}\text { sofa } \rightarrow \text { couch } \\
\text { kitten } \rightarrow \text { cat } \\
\text { parent } \rightarrow \text { father } \\
\text { prince } \rightarrow \text { king }\end{array}$ \\
\hline $\begin{array}{l}\text { Nonequivalent } \\
\text { meaning } \mathrm{b}\end{array}$ & $\begin{array}{l}\text { Associative responses whose } \\
\text { meaning is related but not } \\
\text { equivalent to the cue word }\end{array}$ & $\begin{array}{l}\text { party } \rightarrow \text { celebrate } \\
\text { accountant } \rightarrow \text { numbers } \\
\text { ballgown } \rightarrow \text { graduation }\end{array}$ \\
\hline
\end{tabular}

a This category corresponds to defining synonym, specific synonym, and lexical set in Fitzpatrick (2006, 2007, 2009).

b This category corresponds to other conceptual association in Fitzpatrick (2006, 2007, 2009). 


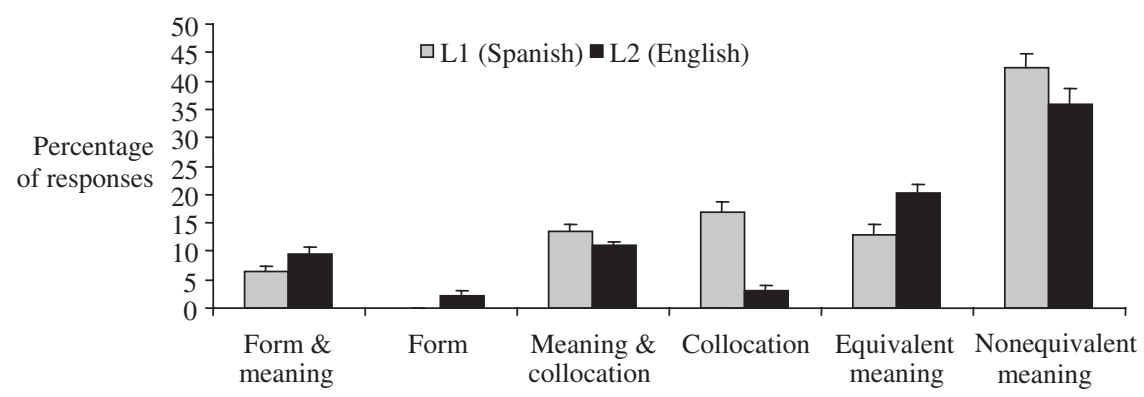

Figure 1. Word association tasks: Percentage of responses within categories showing an interaction between category and language. Error bars show mean plus one standard error.

significant, $F(5,85)=127.05, M S e=48.58, p<.001, \eta^{2}=.88$, with some categories producing more responses than others. The interaction between language and category of response was also significant, $F(5,85)=11.01, M S e=47.74, p<.001, \eta^{2}=.39$. The interaction can be seen in Figure 1. A series of $t$ test comparisons (Bonferroni correction applied, $\alpha=.05$ ) showed significant differences between the L1 and L2 in the proportion of equivalent meaning associations, $t(17)=-3.19, p<.05$; form and meaning associations, $t(17)=-3.05, p<.05$; collocation associations, $t(17)=9.81, p<.001$; and form associations, $t(17)=-3.47, p<.05$. Additionally, the proportion of word association responses related to the cue by nonequivalent meaning were significantly higher than for any other category both in the L1, $t(17)=10.23, p<.001$, and in the L2, $t(17)=8.68, p<.001$.

Comparing the L1 and L2: Response Times per Category. Results were also examined in terms of reaction times to assess the speed of word association responses. However, as can be seen in Figure 1, in their L1, participants did not actually produce any associations that were related only in form to the cue word. Similarly, the proportion of L2 associative responses categorized as collocations was very low; some participants did not produce any responses of this type. Missing values introduce imbalance in ANOVA analyses, making the estimates nonorthogonal and the results unreliable. For this reason, mean reaction times and standard deviations were calculated for only four out of the six original categories: form and meaning, meaning and collocation, equivalent meaning, and nonequivalent meaning. Mean response times and standard errors per language and category are summarized in Figure 2.

A $2 \times 4$ ANOVA with category of response and language as withinsubject factors was conducted. Results revealed a significant main effect of language, with faster responses in the $\mathrm{L} 1$ than in the $\mathrm{L} 2, F(1,17)=$ $12.13, M S e=268,677.95, p<.05, \eta^{2}=.42$. The main effect of category of 


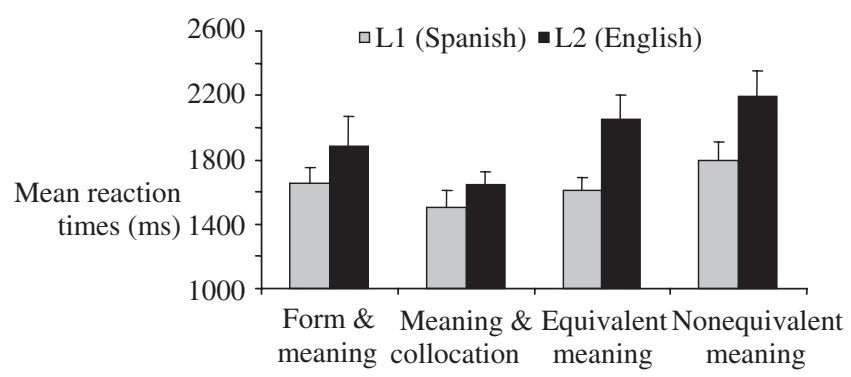

Figure 2. Word association tasks: Mean response times by response category and language. Error bars show mean plus one standard error.

response was also significant, $F(3,51)=15.03, M S e=71,826.05, p<.001$, $\eta^{2}=.47$, with faster responses produced in some categories compared with others. Simple main effects revealed that associations that co-occur in the language and also have a meaning relation (meaning and collocation) were significantly faster than any other response category (comparison with equivalent meaning, $p<.001$; comparison with form and meaning, $p<.05$; comparison with nonequivalent meaning, $p<.001$ ). Similarly, responses with a nonequivalent meaning relation were significantly slower than any other category (comparison with equivalent meaning, $p<.05$; comparison with form and meaning, $p<.01$ ). Only response times with an equivalent meaning relation and those related in form and meaning were not significantly different $(p=.358)$. The interaction between language and category was not significant.

Response Times per Category and Proficiency. The L2 response times for all the participants as a group were slower than in the L1. The average response time per participant and category in the L1 was subtracted from the corresponding average response time in the L2. These differences were correlated with the vocabulary size of each participant (from the EVST) as a proxy for proficiency level. The results

Table 3. Correlations between L2 vocabulary size and L1-L2 response time differences

\begin{tabular}{lcc}
\hline Category & Partial correlation & Significance \\
\hline Equivalent meaning & -.524 & $p<.05$ \\
Nonequivalent meaning & -.767 & $p<.01$ \\
Form and meaning & -.543 & $p<.01$ \\
Meaning and collocation & -.094 & $p=.36$ \\
All categories & -.698 & $p<.01$ \\
\hline
\end{tabular}


(as shown in Table 3) indicate that the difference between L1 and L2 response times decreased with larger L2 vocabulary sizes (a typical measure of L2 proficiency). This was the case for all categories except meaning and collocation.

Generally speaking, L2 response times were faster for participants with larger L2 vocabulary sizes. However, reaction times to the meaning and collocation category (the fastest responses in both the L1 and L2) did not decrease in line with vocabulary size growth.

\section{Lexical Decision Task}

The lexical decision task produced a set of recognition times for each participant for primed words, nonprimed words, and nonwords.

Preparing Data for Analysis. The words used in the primed condition were the Spanish translation equivalents of 18 English cue words used in the word association task. They were considered primed words under the assumption that in the preceding task, participants produced a L2 word association response after translating the cue word into its L1 equivalent. Before analyzing the lexical decision task data, it was therefore necessary to reexamine the word association responses. If participants had not produced a word association response to a L2 cue word, no priming for that particular word and participant could be assumed to have occurred. Recognition times for those words whose L2 translation equivalents had not produced a response in the word association task were therefore deleted (13\%). Additionally, reaction times were also deleted for those words that belonged to the nonprimed condition but had coincidentally been produced as a response in the L1 word association task (7\%). This was because, in these cases, repetition priming had accidentally occurred for words belonging to the nonprimed condition. Finally, those words from the nonprimed condition whose translation equivalents had coincidentally been produced as an association response in the L2 word association task were considered to fall within the potentially language-mediated (and therefore primed) items. For example, if black was produced in response to the cue word night in the English word association task, the item negro "black" was considered to have been primed. Reaction times for those words were therefore transferred to the primed condition (5\%). On the basis of the remaining latencies, the overall mean and standard deviation of each participant's word recognition time were computed and response times three standard deviations above or below each participant's mean were removed $(2.22 \%)$. Results from one participant were discarded due to an interruption during testing. 
Priming Effects. Reaction times were examined for the group $(N=23)$ as a whole. An ANOVA was carried out with proficiency as a betweensubjects factor and priming as a within-subjects factor. A main priming effect was found, $F(1,21)=4.74, M S e=845.32, p<.05$. No other main effects or interactions were found. Although in the absence of an interaction, no further analyses would be required, given this study's focus on the relationship between L1 mediation and level of L2 proficiency, two further analyses were computed: one for the participants $(n=9)$ whose EVST scores were below the group mean of 7,192 and one for the participants $(n=14)$ who scored higher than the group mean on this test. A summary of mean reaction times, standard deviations, and errors for each of these groups is presented in Table 4.

Two $t$ test comparisons were carried out (Bonferroni correction applied, $\alpha=.05$ ). For those participants with a higher proficiency level in English, nonsignificant differences between primed and nonprimed conditions were found $(p=.230)$. However, the difference between primed and nonprimed items was significant for those participants with a lower proficiency level in English, $t(9)=2.47, p<.05$.

\section{DISCUSSION}

Analysis of the word association data revealed main effects of language and category. The nonequivalent meaning category accounted for the greatest number of responses, both in the L1 (42\%) and L2 (36\%). Significant differences were also found in the equivalent meaning category, with more responses produced in the L2 (20\%) than L1 (13\%). The proportion of responses was also higher in the L2 than L1

Table 4. Response times by group in the lexical decision task

\begin{tabular}{lccc}
\hline Group & Set A (primed) & Set B (not primed) & Difference \\
\hline \multicolumn{2}{l}{ High-proficiency participants $(n=14)$} & & \\
$M$ & 602 & 617 & 15 \\
$S D$ & 71 & 93 & \\
$\%$ Error & .46 & .46 & \\
Low-proficiency participants $(n=9)$ & & 27 \\
$M$ & 615 & 642 & \\
$S D$ & 117 & 113 & \\
$\%$ Error & .46 & .23 & \\
All participants $(N=23)$ & & \\
$M$ & 607 & 627 & \\
$S D$ & 99 & 89 & \\
$\%$ Error & .92 & .69 & \\
\hline
\end{tabular}


for the form category (L2: $2 \%, \mathrm{~L} 1: 0 \%)$ and form and meaning (L2: $9 \%$, L1: $6 \%)$. In contrast, more collocations were produced in the L1 (17\%) than L2 (3\%). The proportion of responses with a nonequivalent meaning relation and with a combined relation of meaning and collocation were similar in both languages. Main effects of language and category of response were also found in the reaction time data. Participants produced word association responses faster in the L1 than L2, although the difference between L1 and L2 reaction times decreased as proficiency increased. Additionally, responses that co-occur in the language and have a meaning relation with the cue word (meaning and collocation) were produced significantly faster $(1,577 \mathrm{~ms})$ than any other type of response. The next fastest responses were those associations related in form and meaning to the cue word $(1,770 \mathrm{~ms})$. These were not significantly faster than associations with an equivalent meaning relation $(1,833 \mathrm{~ms})$. However, associations with a nonequivalent meaning relation were elicited significantly more slowly $(1,996$ ms) than responses in any other category type. Thus, responses whose meaning was related but not equivalent to the cue word were both the most frequently produced and the slowest associations produced in both languages. These results suggest that at the time of producing associates, words with a direct connection to the cue word (i.e., with an equivalent meaning) or connected by more than one route (form and meaning, meaning and collocation) are quickly and strongly activated.

Findings from the lexical decision task indicate that the group of participants as a whole was faster at recognizing the primed Spanish words. These were the translation equivalents of English words used as cues in the previously completed word association task. This suggests that the (L1) Spanish words were somehow activated during the (L2) English word association task. When examining the group in terms of their proficiency levels, the priming effect was only found in those participants with lower proficiency scores. Possible interpretations and implications of these findings merit further discussion.

\section{Response Categories and Response Times}

The response time data have yielded a few main findings. The first of these-that L2 responses are fewer in number and generally slower than $\mathrm{L} 1$ responses-is reasonably straightforward and uncontroversial. It supports findings from picture-naming studies (e.g., Chen \& Leung, 1989; Kroll \& Curley, 1988; Potter, So, Von Eckardt, \& Feldman, 1984) that suggest that it takes longer to process L2 than L1 lexical items, perhaps due to the developmental nature of the $\mathrm{L} 2$ lexicon and to the 
smaller vocabulary sizes in L2 as compared to L1. Additionally, the correlation of $-.698(p<.01)$ found between the L1-L2 response time differences and the measure of vocabulary size implies that L2 response times will become faster as proficiency increases.

The second finding is that L2 category reaction times broadly mirror L1 reaction times. For both languages, participants took more time to produce nonequivalent meaning associations (those which have a clear meaning connection but do not have a straightforward relationship of synonymy, hyponymy, etc.) than to produce associations that are linked through meaning and collocation (e.g., spider $\rightarrow$ web). This effect was so large that the mean response times for meaning and collocation responses in the $\mathrm{L} 2$ were even faster $(1,646 \mathrm{~ms})$ than the mean response times for nonequivalent meaning in L1 (1,795 ms).

In terms of the number of responses given, some differences between the L1 and L2 emerged as the interaction between language and type of responses indicates. A novel finding here was the fact that a higher proportion of responses with an equivalent meaning were produced in the L2 compared with the L1. This difference suggests that the lexicosemantic organization of the L2 might be more constrained by general conceptual knowledge (e.g., most L2 speakers of English would associate sheep with animal) and less characterized by the conventional use of the language (e.g., some native English speakers might also associate sheep with black because of the idiom black sheep). This idea has additional support in the significant differences found between the L1 and L2 in the number of associates produced because they co-occur in the language with the cue word (collocations). Most of these responses were produced in the L1 (17\%), with very few in the L2 (3\%).

Words associated as a result of their frequency of co-occurrence in the spoken or written language have been traditionally coded as syntagmatic responses and their production in association tasks is considered by some researchers as an index of a L2 lexicon in the early stages of development (e.g., Politzer, 1978; Söderman, 1993). The results found in the present study contradict this assumption because more associated responses that co-occur in the natural language were found in the L1 than in the L2. A recent study by Nissen and Henriksen (2006) also found "a surprising majority of syntagmatic responses in the L1 test" (p. 389). When looking at those words that not only co-occur in the language but also have a meaning relation (meaning and collocation), the difference between the L1 and L2 was not significant. Finally, a significantly higher proportion of form-related associations were produced in the L2 than in the L1. This suggests that L2 associative activations have stronger phonological-orthographical lexical reliance than L1 words. This supports suggestions from Meara $(1978,1983)$ and Laufer (1989) that L2 lexical organization may be heavily based on phonological and orthographic information. Overall, these results also concur with 
Grosjean (1989), showing that lexical organization of the L1 and of the L2 are not at all times comparable.

There are two reasons why form-based associations might be expected to be more salient in the L2 than in the L1. First, in the L2 vocabulary acquisition process, it is common for attention to be paid to the form of the word-its morphological structure, other members of the word family, the way in which it is inflected, the matching of orthographic to phonological features, and so on. In L1 acquisition, this is rarely the case-the focus is instead on the packaging and labeling of concepts. Second, this evidence of form-based activation could be a consequence of the state of development of the L2 lexicon, with subsets of words having stronger lexical connections (related in form) than semantic connections (related in meaning). The revised hierarchical model (Kroll \& Stewart, 1994) predicts that, at least at the first stages of learning, L2 words develop weak semantic connections to their meanings and strong lexical connections with their L1 counterparts. The model does not describe the strength of lexical connections within the L2 lexicon nor whether they might be different from the lexical interconnectivity of words in L1. The existence (and nature) of these intralingual links between L2 items that share orthographic or phonological features is a question worth exploring in subsequent research.

It is interesting to note that the category identified as yielding the slowest responses-namely, nonequivalent meaning-is the one in which, by far, the highest number of responses are produced in both the L1 and L2. The fastest L1 and L2 responses were in the categories of form and meaning and meaning and collocation, but these represent the lowest numbers of responses for both the L1 and L2. It appears, then, that there is an inverse relationship between the number of responses produced in each category and the speed with which they are produced. This raises a number of challenging issues, including the question of why the majority of the participants' responses are in categories that apparently are the least efficiently (or the least quickly) accessed. It also raises questions about the interpretations of findings from earlier studies, in which the number of responses per category was the only measure available.

One possible explanation here is that links based on form and meaning or on meaning and collocation are the most readily accessed where they exist, but in many (or even most) cases, no such links exist (e.g., for the cue words daffodil, barrister, parent). Form and meaning links tend to be more available for words that are, or that form part of, polymorphemic words (e.g., housework, hairdresser, newsagent, and milkman). Meaning and collocation links tend to be found for words that are part of a binomial pair (brother-sister) or that are antonyms (black-white).

It could be the case, then, that it is the combined activation effect of a concept link and a collocation link that produces a faster 
response. Thus, although the cue word sister elicited daughter, mum, son, and even nun as responses, the response item brother-which has a collocational link (it co-occurs more frequently with sister) in addition to its meaning link-is the fastest response. If the word association event is conceptualized in terms of activations, then it might be suggested that there are a number of different kinds of potential activation triggers (meaning, collocation, form) and that the activation event is stronger, or faster, if more than one of these is present. However, this does not occur often because there are few words that have more than one strong link.

Another possible explanation for this is the likelihood that in the case of nonequivalent meaning responses, most cue words have links to a large number of lexical items that would fit this category. In the L2 data, nonequivalent meaning responses to the cue word bear included forest, honey, big, cave, and white; in most reasonably advanced individual lexicons, it is likely that the word bear (animal) is linked to words such as these as well as, perhaps, fur, fierce, Canada, zoo, and so on (to cite examples from Kiss, Armstrong, Milroy, \& Piper, 1973). These responses might correspond to De Groot's (1992) conceptual features-the various aspects of meaning of a word. It is possible that the cue word bear activates several of these conceptual links, so that perhaps the competition between them, and the selection of just one, results in a longer response time. However, the fastest responses in the current study, on average, were for responses linked to the cue word not only by meaning but also by collocation. For example, some of the participants of the current study produced the association pair bear $\rightarrow$ teddy. The speed advantage in this category of responses may be due to the presence of two activation triggers. A complementary explanation here, though, is that for any given cue, there are fewer potential responses in this meaning and collocation category, and therefore less competition and faster responses.

A final point of consideration is that the present study was primarily interested in the subjects' responses and therefore all analyses can be regarded as by-subject analyses. However, it could be the case that features of the cue words themselves might have an influence on the association responses. This is indicated by Brysbaert, Van Wijnendaele, \& De Deyne (2000) in their analysis of the influence of cue word properties on reaction times. Additionally, our observations about binomials and polymorphemic words seem to support the idea that characteristics of the cue words are important. To understand the influence of cue words on reaction times and type of associative link, a byitems analysis would be necessary. In this case, a selection of cues likely to elicit every kind of response, and a larger group of respondents would be required to make a comparative analysis of response types to each cue statistically robust. Certainly, this analysis would enhance 
and progress our understanding of the nature of word association responses.

\section{L2-L1 Priming Effect: The Lexical Decision Task}

The priming effect found for items that were L1 translation equivalents of L2 cue words supports the hypothesis that L2 associations are mediated by the L1. Figure 3 illustrates this process with an example from the L2 word association task, in which the participant provided the response car to the cue lorry. In the subsequent lexical decision task, participants displayed a priming effect for camion "lorry," despite the fact that it had not appeared as either a cue or a response item in the L1 word association task. This indicates that the activation of camion "lorry" must have occurred during the lorry-car association event. It is important to note that it is entirely possible that more than one intermediate word in the L1 is activated during this process, and it seems reasonable to suggest that this might be the $\mathrm{L} 1$ translation equivalent of the $\mathrm{L} 2$ response word, so that the association event might look more like that in Figure 4. This is entirely speculative and difficult to investigate using the priming paradigm because associative responses cannot be predetermined and thus included as potentially primed stimuli in the lexical decision task-they vary from one participant to another.

The results of the lexical decision task indicate that L2 associations are possibly mediated through at least one translation equivalent. Assuming that word association responses relate at some level to concepts (in other words, in the process of associating one lexical item with another, the meaning or concept related to those items is accessed at some level), this finding is clearly supportive of Kroll and Stewart's (1994) revised hierarchical model. Although the priming effect was

Cue word (L2)

LORRY

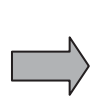

Intermediate L1 link

camión "lorry"
Response (L2)

CAR

Figure 3. Example of lorry $\rightarrow$ car association process mediated by the L1.

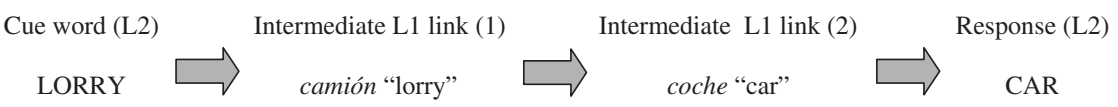

Figure 4. Example of lorry $\rightarrow$ car association process mediated by two L1 links. 
shown across all participants, the effect had a larger impact in the low-proficiency group. This is also in line with their model, as it follows Kroll's (1993) claim for the dynamic and developmental nature of the model: "the strength of the connections between the L1 and L2 lexicons ... is hypothesized to vary as a function of relative fluency in L2" (pp. 69-70). The implication here is that as proficiency in the L2 increases, this mediation of L2 associations through the L1 ceases to happen in a significant way. The possibility that the priming effect observed was due to the activation of the concepts rather than lexical items seems unlikely. If conceptual activation was responsible for the priming effects, different results would be expected—namely, a stronger priming effect for high- than low-proficiency bilinguals. If (as assumed by most, if not all, models of bilingual word production and recognition) the semantic representations are shared (in part or completely) between the bilingual's two languages, then the concepts of the primed stimuli used in the L1 lexical decision task would have been activated by all participants (as the results suggest) but possibly slightly more by highproficiency bilinguals, given that their semantic-lexical connections are assumed to be stronger than those of low-proficiency bilinguals. This is not what the mean differences and post hoc $t$ test analyses suggest.

\section{CONCLUSION}

In this study, L1 and L2 word associations were examined using a categories-of-response framework. The results showed that associations with more than one type of activation route (i.e., form and meaning or meaning and collocation) were produced most quickly in the L1 and L2. Responses with a nonequivalent meaning link to the cue word (i.e., with some conceptual link, excluding synonyms, antonyms, superordinate categories, etc.) were the slowest to be produced but were also the most frequent type of association produced in both languages. L2 response times were larger than in the $\mathrm{L} 1$, but the difference between $\mathrm{L} 1$ and L2 response times became smaller as proficiency increased. Finally, a priming effect was found for L1 translations of L2 word association cues for the low-proficiency bilinguals, indicating that L2 associations are mediated through L1 translation equivalents. Although the findings broadly support Kroll and Stewart's (1994) developmental model of SLA, they also raise questions about the nature of intralingual connections during the acquisition processes and the particular salience of word form during SLA. Possible explanations of response time differences between categories focus, on the one hand, on the role of different kinds of activation triggers (meaning, collocation, form, or combinations of these) and, on the other hand, on the effect of several potential responses competing for selection. The detection, in less proficient 
learners only, of a L1 priming effect from the L2 association task not only supports the revised hierarchical model (Kroll \& Stewart) but also suggests the existence of a threshold level of L2 proficiency, beyond which L1 mediation is not significant. Significant findings in terms of category reaction time differences suggest that word association reaction time data might inform understanding of storage and activation in the bilingual lexicon.

(Received 1 June 2010)

\section{REFERENCES}

Albrechtsen, D., Haastrup, K., \& Henriksen, B. (2008). Vocabulary and writing in a first and second language: Processes and development. New York: Palgrave Macmillan.

Altarriba, J., Bauer, L. M., \& Benvenuto, C. (1999). Concreteness, context availability, and imageability ratings and word associations for abstract, concrete, and emotion words. Behavior Research Methods, Instruments, and Computers, 31, 578-602.

Altmann, G. T. M. (1997). The ascent of Babel: An exploration of language, mind, and understanding. Oxford: Oxford University Press.

Becker, S., Moscovitch, M., Behrmann, M., \& Joordens, S. (1997). Long-term semantic priming: A computational account and empirical evidence. Journal of Experimental Psychology: Learning, Memory, and Cognition, 23, 1059-1082.

Besner, D., Smith, M. C., \& MacLeod, C. M. (1990). Visual word recognition: A dissociation of lexical and semantic processing. Journal of Experimental Psychology: Learning, Memory, and Cognition, 16, 862-869.

Bird, H., Franklin, S., \& Howard, D. (2001). Age of acquisition and imageability ratings for a large set of words, including verbs and function words. Behavior Research Methods, Instruments, and Computers, 33, 73-79.

Bodner, G. E., \& Masson, M. E. J. (2003). Beyond spreading activation: An influence of relatedness proportion on masked semantic priming. Psychonomic Bulletin and Review, 10, 645-652.

Brysbaert, M., \& Ghyselinck, M. (2006). The effect of age of acquisition: Partly frequency related, partly frequency independent. Visual Cognition, 13, 992-1011.

Brysbaert, M., Van Wijnendaele, I., \& De Deyne, S. (2000). Age-of-acquisition effects in semantic processing tasks. Acta Psychologica, 104, 215-226.

Chen, H.-C., \& Leung, Y.-S. (1989). Patterns of lexical processing in a nonnative language. Journal of Experimental Psychology: Learning, Memory, and Cognition, 15, 316-325.

Chen, H.-C., \& Ng, M.-L. (1989). Semantic facilitation and translation priming effects in Chinese-English bilinguals. Memory and Cognition, 17, 454-462.

Collins, A. M., \& Quillian, M. R. (1969). Retrieval time from semantic memory. Journal of Verbal Learning and Verbal Behavior, 8, 240-247.

Costa, A., \& Caramazza, A. (1999). Is lexical selection in bilingual speech production language-specific? Further evidence from Spanish-English and English-Spanish bilinguals. Bilingualism: Language and Cognition, 2, 231-244.

Damian, M. F., \& Als, L. C. (2005). Long-lasting semantic context effects in the spoken production of object names. Journal of Experimental Psychology: Learning, Memory and Cognition, 31, 1372-1384.

De Groot, A. M. B. (1992). Bilingual lexical representation: A closer look at conceptual representations. In R. Frost \& L. Katz (Eds.), Orthography, phonology, morphology, and meaning (pp. 389-412). Amsterdam: North-Holland.

De Groot, A. M. B., Borgwaldt, S., Bos, M., \& Van den Eijnden, E. (2002). Lexical decision and word naming in bilinguals: Language effects and task effects. Journal of Memory and Language, 47, 91-124. 
Deese, J. (1962). Form class and the determinants of association. Journal of Verbal Learning and Verbal Behavior, 1, 79-84.

Entwisle, D. R. (1966). The word associations of young children. Baltimore: Johns Hopkins University Press.

Entwisle, D. R., Forsyth, D. F., \& Muuss, R. (1964). The syntagmatic-paradigmatic shift in children's word associations. Journal of Verbal Learning and Verbal Behavior, 3, 19-29.

Ervin, S. (1961). Changes with age in the verbal determinants of word association. American Journal of Psychology, 74, 361-372.

Fitzpatrick, T. (2006). Habits and rabbits: Word associations and the L2 lexicon. EUROSLA Yearbook, 6, 121-145.

Fitzpatrick, T. (2007). Word association patterns: Unpacking the assumptions. International Journal of Applied Linguistics, 17, 319-331.

Fitzpatrick, T. (2009). Word association profiles in a first and second language: Puzzles and problems. In T. Fitzpatrick \& A. Barfield (Eds.), Lexical processing in second language learners (pp. 38-52). Clevedon, UK: Multilingual Matters.

Forster, K. (1992). Memory-addressing mechanisms and lexical access. In R. Frost \& L. Katz (Eds.), Orthography, phonology, morphology, and meaning (pp. 413-434). Amsterdam: North-Holland.

Grabois, H. (1999). The convergence of sociocultural theory and cognitive linguistics: Lexical semantics and the L2 acquisition of love, fear and happiness. In G. B. Palmer \& D. J. Occhi (Eds.), Languages of sentiment: Cultural constructions of emotional substrates (pp. 201-233). Amsterdam: Benjamins.

Greidanus, T., \& Nienhuis, L. (2001). Testing the quality of word knowledge in a second language by means of word associations: Types of distractors and types of associations. Modern Language Journal, 85, 567-577.

Grosjean, F. (1989). Neurolinguists, beware! The bilingual is not two monolinguals in one person. Brain and Language, 36, 3-15.

Grossi, G. (2006). Relatedness proportion effects on masked associative priming: An ERP study. Pscychophysiology, 43, 21-30.

Hermans, D., Bongaerts, T., De Bot, K., \& Schreuder, R. (1998). Producing words in a foreign language: Can speakers prevent interference from their first language? Bilingualism: Language and Cognition, 1, 213-229.

Jared, D., \& Kroll, J. F. (2001). Do bilinguals activate phonological representations in one or both of their languages when naming words? Journal of Memory and Language, 44, 2-31.

Joordens, S., \& Becker, S. (1997). The long and short of semantic priming effects in lexical decision. Journal of Experimental Psychology: Learning, Memory, and Cognition, 23, 1083-1105.

Kiss, G. R., Armstrong, C., Milroy, R., \& Piper, J. (1973). An associative thesaurus of English and its computer analysis. In A. J. Aitken, R. W. Bailey, \& N. Hamilton-Smith (Eds.), The computer and literary studies (pp. 153-65). Edinburgh, UK: Edinburgh University Press.

Koda, K. (1997). Orthographic knowledge in L2 lexical processing: A cross-linguistic perspective. In J. Coady \& T. Huckin (Eds.), Second language vocabulary acquisition (pp. 35-52). New York: Cambridge University Press.

Kohnert, K. J., Bates, E., \& Hernandez, A. E. (1999). Balancing bilinguals: Lexical-semantic production and cognitive processing in children learning Spanish and English. Journal of Speech, Language, and Hearing Research, 42, 1400-1413.

Kroll, J. F. (1993). Accessing conceptual representations for words in a second language. In R. Schreuder \& B. Weltens (Eds.), The bilingual lexicon (pp. 53-81). Amsterdam: Benjamins.

Kroll, J. F., \& Curley, J. (1988). Lexical memory in novice bilinguals: The role of concepts in retrieving second language words. In M. Gruneberg, P. Morris, \& R. Sykes (Eds.), Practical aspects of memory (pp. 389-395). New York: Wiley.

Kroll, J. F., \& Stewart, E. (1994). Category interference in translation and picture naming: Evidence for asymmetric connections between bilingual memory representations. Journal of Memory and Language, 33, 149-174.

Kroll, J. F., \& Tokowicz, N. (2005). Models of bilingual representation and processing: Looking back and to the future. In J. F. Kroll \& A. M. B. De Groot (Eds.), Handbook of bilingualism: Psycholinguistic approaches (pp. 531-53). Oxford: Oxford University Press. 
Kruse, H., Pankhurst, J., \& Sharwood Smith, M. (1987). A multiple word association probe in second language acquisition research. Studies in Second Language Acquisition, 9, 141-154.

La Heij, W., Hooglander, A., Kerling, R., \& Van der Velden, E. (1996). Nonverbal context effects in forward and backward word translation: Evidence for concept mediation. Journal of Memory and Language, 35, 648-665.

Laufer, B. (1989). A factor of difficulty in vocabulary learning: Deceptive transparency. AILA Review, 6, 10-20.

Lippman, M. Z. (1971). Correlates of contrast word associations: Developmental trends. Journal of Verbal Learning and Verbal Behavior, 10, 392-399.

Maréchal, C. (1995). The bilingual lexicon: Study of French and English word association responses of advanced learners of French. Unpublished master's thesis, University of Dublin.

McNeill, D. (1966). A study of word association. Journal of Verbal Learning and Verbal Behavior, 5, 548-557.

Meara, P. M. (1978). Learners' word associations in French. Interlanguage Studies Bulletin, 3, 192-211.

Meara, P. M. (1983). Word associations in a foreign language: A report on the Birkbeck vocabulary project. Nottingham Linguistic Circular, 11, 29-38.

Meara, P. M. (2007). Growing a vocabulary. EUROSLA Yearbook, 7, 49-65.

Meara, P. M., \& Jones, G. (1990). Eurocentres vocabulary size test: 10KA. Zurich: Eurocentres.

Meara, P. M., Lightbown, P. M., \& Halter, R. H. (1994). The effect of cognates on the applicability of YES/NO vocabulary tests. Canadian Modern Language Review, 50, 296-311.

Monsell, S. (1985). Repetition and the lexicon. In A. W. Ellis (Ed.), Progress in the psychology of language (pp. 147-195). Mahwah, NJ: Erlbaum.

Morrison, C. M., \& Ellis, A. W. (2000). Real age of acquisition effects in word naming and lexical decision. British Journal of Psychology, 91, 167-180.

Nelson, K. (1977). The syntagmatic-paradigmatic shift revisited: A review of research and theory. Psychological Bulletin, 84, 93-116.

Nissen, H. B., \& Henriksen, B. (2006). Word class influence on word association test results. International Journal of Applied Linguistics, 16, 389-408.

Odlin, T. (1989). Language transfer: Cross linguistic influence in language learning. New York: Cambridge University Press.

Orita, M. (2002). Word associations of Japanese EFL learners and native speakers: Shifts in response type and distribution and the associative development of individual words. Annual Review of English Language Education in Japan, 13, 111-120.

Pérez, M. A., \& Navalón, C. (2005). Objective-AoA norms for 175 names in Spanish: Relationships with other psycholinguistic variables, estimated AoA, and data from other languages. European Journal of Cognitive Psychology, 17, 179-206.

Politzer, R. L. (1978). Paradigmatic and syntagmatic associations of first year French students. In V. Hausa (Ed.), Papers in linguistics and child language (pp. 203-210). Berlin: Mouton de Gruyter.

Potter, M. C., So, K.-F., Von Eckardt, B., \& Feldman, L. B. (1984). Lexical and conceptual representation in beginning and more proficient bilinguals. Journal of Verbal Learning and Verbal Behavior, 23, 23-38.

Randall, M. (1980). Word association behaviour in learners of English as a foreign language. Polyglot, 2, B5-D1.

Riegel, K., \& Zivian, I. (1972). A study of inter- and intralingual associations in English and German. Language Learning, 22, 51-63.

Rodriguez-Aranda, C., \& Martinussen, M. (2006). Age-related differences in performance of phonemic verbal fluency: A meta-analytic study. Developmental Neuropsychology, 30, 697-717.

Schmitt, N. (1998). Quantifying word association responses: What is native-like? System, $26,389-401$.

Schriefers, H., Meyer, A. S., \& Levelt, W. J. M. (1990). Exploring the time course of lexical access in language production picture-word interference studies. Journal of Memory and Language, 1, 86-102.

Sholl, A., Sankaranarayanan, A., \& Kroll, J. F. (1995). Transfer between picture naming and translation: A test of asymmetries in bilingual memory. Psychological Science, 6, 45-49. 
Singleton, D. (1999). Exploring the second language mental lexicon. New York: Cambridge University Press.

Söderman, T. (1993). Word associations of foreign language learners and native speakers: Different response types and their relevance to lexical development. In B. Hammerberg (Ed.), Problems, process and product in language learning (pp. 157-169). Abo, Finland: Abo Academic.

Sökmen, A. (1993). Word association results: A window to the lexicons of ESL students. JALT Journal, 15, 135-150.

Tse, C.-S., \& Neely, J. H. (2007). Semantic and repetition priming effects for Deese/RoedigerMcDermott (DRM) critical items and associates produced by DRM and unrelated study lists. Memory and Cognition, 35, 1047-1066.

Van Hell, J. G., \& De Groot, A. M. B. (1998). Conceptual representation in bilingual memory: Effects of concreteness and cognate status in word association. Bilingualism: Language and Cognition, 1, 193-211.

Wickelgren, W. A. (1977). Learning and memory. Englewood Cliffs, NJ: Prentice Hall.

Wilks, C. (2009). Tangled webs. .. : Complications in the exploration of L2 lexical networks. In T. Fitzpatrick \& A. Barfield (Eds.), Lexical processing in second language learners (pp. 25-37). Clevedon, UK: Multilingual Matters.

Wilks, C., \& Meara, P. M. (2007). Implementing graph theory approaches to the exploration of density and structure in L1 and L2 word association networks. In H. Daller, J. Milton, \& J. Treffers-Daller (Eds.), Modelling and assessing vocabulary knowledge (pp. 167-181). New York: Cambridge University Press.

Wilks, C., Meara, P. M., \& Wolter, B. (2005). A further note on simulating word association behaviour in a second language. Second Language Research, 21, 359-372.

Wolter, B. (2001). Comparing the L1 and L2 mental lexicon. Studies in Second Language Acquisition, 23, 41-69

Wolter, B. (2002). Assessing proficiency through word associations: Is there still hope? System, 30, 315-329.

Zareva, A., Schwanenflugel, P., \& Niklova, P. (2005). Relationship between lexical competence and language proficiency. Studies in Second Language Acquisition, 27, 567-595.

Zevin, J. D., \& Seidenberg, M. S. (2002). Age of acquisition effects in word reading and other tasks. Journal of Memory and Language, 47, 1-29.

Zevin, J. D., \& Seidenberg, M. S. (2004). Age of acquisition effects in reading aloud: Tests of cumulative frequency and frequency trajectory. Memory and Cognition, 32, 31-38. 